\title{
Aluminum Contents in Dry Leaves and Infusions of Commercial Black and Green Tea Leaves: Effects of Sucrose and Ascorbic Acid Added to Infusions
}

\author{
Diego Armando Bárcena-Padilla, Marisela Bernal-González, Amalia Panizza-de-León, Rolando Sal- \\ vador García-Gómez, Carmen Durán-Domínguez-de-Bazúa
}

Facultad de Química, Universidad Nacional Autónoma de México, México City, Mexico.

Email: \{die_gool_86, marisela_bernal2000\}@yahoo.com.mx, amalia.panizza@gmail.com, rolandoga2000_a@yahoo.com, mcduran@unam.mx

Received January $29^{\text {th }}, 2011$; revised June $28^{\text {th }}, 2011$; accepted July $10^{\text {th }}, 2011$.

\begin{abstract}
Tea consumption has increased due to its beneficial effects. Results from a lab study on the effect of sucrose (5 $\mathrm{g}$ per cup, $150 \mathrm{~mL}$ ) and/or ascorbic acid $(2 \mathrm{~mL}$ per cup, $150 \mathrm{~mL}$ ) on dissolved aluminum compounds during the infusion of two commercial types of dry tea leaves (black, green) with boiling water (5, 15 min infusion time) are presented. Factors influencing the presence of dissolved aluminum in the infusions of both tea leaves were infusion time and sugar contents, as well as the interaction between ascorbic acid and sucrose $(p<0.05)$. Aluminum contents found after 15 min of infusion were $0.7 \mathrm{mg} \cdot \mathrm{L}^{-1}$ for black tea infusions added with sugar, and $0.69 \mathrm{mg} \cdot \mathrm{L}^{-1}$ for green tea added with both sugar and ascorbic acid. Both concentrations are higher than the level accepted in Mexico for drinking water (there is no act concerning tea infusions), that is $0.2 \mathrm{mg} \cdot \mathrm{L}^{-1}$.
\end{abstract}

Keywords: Aluminum Contents, Commercial Black and Green Tea Dry Leaves, Infusions, Sucrose, Ascorbic Acid

\section{Introduction}

Tea is one of the most popular non alcoholic drinks in the world, particularly in Asia. In the last years tea consumption, and particularly green tea, has increased, due to the general belief that it has beneficial effects to human health such as anti-mutagenic, anti-cancer, and antioxidant properties [1]. Mexico, as other countries, has increased its consumption at an annual rate of $20 \%[2,3]$.

Tea leaves (Camellia sinensis) are among the most conspicuous vegetal species recognized as aluminum accumulators, reaching contents up to $10,000 \mathrm{mg} \cdot \mathrm{kg}^{-1}$ [4]. Commercial teas, in spite of the fact of being produced from young leaves shoots, contain relatively high concentrations of aluminum, becoming a potential source of bioavailable aluminum in the diet [5-9]. Matsumoto et al. [4] have reported concentrations around $30,000 \mathrm{mg} \cdot \mathrm{kg}^{-1}$ of aluminum in old tea dry leaves. Ruan and Wong [3] mentioned concentrations of aluminum in some tea varieties from 468 to $930 \mathrm{mg} \cdot \mathrm{kg}^{-1}$. For many years alumi- num has been considered innocuous for human beings [10], since most chemical forms are not damaging for living organisms. However, if $\mathrm{pH}$ soil values are low, aluminum tends to form chemical species that are potentially absorbed by plants, especially tea $[11,12]$, and become toxic for living organisms [13]. In this sense, there has been controversy on the impact of this metal on biological systems particularly in the last years [14]. Concerning human health recent studies have demonstrated that bioavailable aluminum is related to some diseases such as Alzheimer, Parkinson, and dialysis encephalopathy [15].

Aluminum concentrations in tea products and its dissolution during the preparation of infusions has been investigated by Flaten [16], Fung et al. [12], Moghaddam et al. [17], and Wong et al. [8,18]. So far, the effects of sucrose and/or lemon juice, as ascorbic acid, on the leaching out of aluminum from the dry tea leaves to water during infusion have not been assessed. 
The objective of this research was to quantify the content of dissolved aluminum in commercial green and black dry leaves tea infusions adding or not sucrose and/or ascorbic acid at two infusion times.

\section{Materials and Methods}

A previous market study was carried out in several Mexico City supermarkets to determine which were the most popular brands of commercial green and black tea among the consumers [19]. As a result two brands, "A" for green tea, and " $\mathrm{B}$ " for black tea, were chosen. Two randomly chosen packages of each brand were taken and brought to the laboratories. The contents of several pouches were mixed to have a homogeneous lot for each type of tea that would be subjected to a microwave digestion. A single pouch contents of black and green tea was also taken to corroborate if statistically significant differences were found with the homogenized lot. The covering material of one of the pouches that could be leached out to the infusions (gauzy material) was analyzed to assess if aluminum was detected. From both homogeneous lots 8 samples (4 for each type of tea) were digested in a Berghof-MWS-1 microwave oven (Germany), according to Bárcena-Padilla [19] pre-established conditions. To determine the contents of aluminum of the samples, atomic absorption spectroscopy (AAS) was the technique used. Analyses were carried out in the Laboratory for Atomic Absorption of the UNAM Faculty of Chemistry (Laboratorio de Absorción Atómica de la USAI, Unidad de Servicios de Apoyo a la Investigación, Facultad de Química, UNAM). The same technique was used for the infusions.

\subsection{Characterization of the Infusions}

A four-factor experimental design with two levels per factor was performed, considering duplicates for all samples. Figure 1 shows the experimental design.

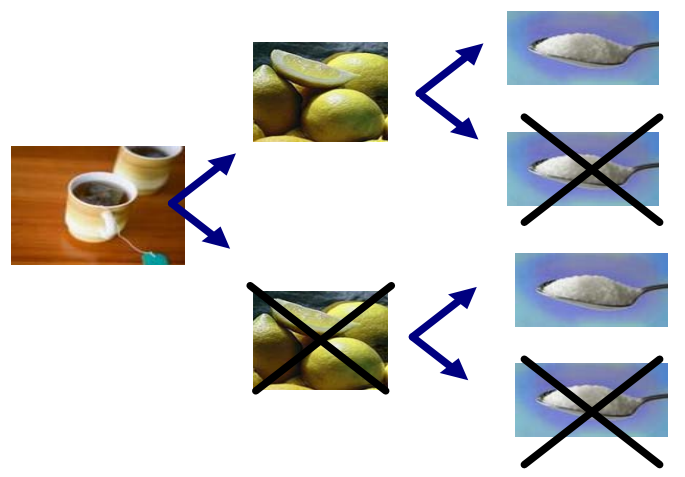

Figure 1. Experimental design for the preparation of green and black tea infusions $(5,15 \mathrm{~min})$ with and without sucrose and ascorbic acid simulating lemon juice.
Factor 1: Tea type (Green and black tea leaves).

Factor 2: Ascorbic acid addition to simulate lemon juice (With and without addition, $2 \mathrm{~mL}$ ).

Factor 3: Sucrose contents (With and without addition, 2 teaspoons $=5 \mathrm{~g}$ ).

Factor 4: Infusion time (5, 15 minutes).

Commercial bottle drinking water was brough to boiling temperature and $150 \mathrm{~mL}$ were poured on each of the beakers that contained the tea leaves pouches. Sucrose (ca. $5 \mathrm{~g}$ ), and/or ascorbic acid (ca. $2 \mathrm{~mL}$ ), were also added. Infusion times considered were 5 and 15 minutes. After the infusion time was over, liquid was drained. There were 32 samples to be digested and sent to AAS analysis. Water was also analyzed to determine its aluminum contents, since in Mexico many potabilization plants use aluminum compounds within the process [20]. Aluminum contents found in water were deducted from the one determined in the infusions.

Statistical analyses of all experimental data were carried out using Statgraphics Plus 5.

\section{Results and Discussion}

Table 1 presents the concentrations of aluminum found in the dry leaves of both commercial teas considered. As mentioned before, black and green tea commercial brands selected were those with the highest demand in several supermarkets, in Mexico City, according to a preference study previously performed [19].

These contents agree with literature data reported by other researchers $[3,4,17]$.

Sucrose and drinking water were analyzed to corroborate its aluminum contents. Also, the material of one pouch was analyzed for aluminum contents.

Table 2 shows the results found. These results indicate that sugar and the pouch material were not a factor to be considered. However, drinking water had very high aluminum contents, probably due to the potabilization methods commonly used in Mexico (that include the addition of alum to flocculate and precipitate water impurities). This amount was deducted from the infusions data obtained from the atomic absorption analyses.

Table 3 shows the data obtained from the infusions obtained for both types of tea. All of them exceed the maximum allowed contents for drinking water of the Mexican Standards, $0.2 \mathrm{mg} \cdot \mathrm{L}^{-1}$ or $0.2 \mathrm{mg} \cdot \mathrm{kg}^{-1}$ [21].

According to the variance analysis, no significant differences among the two commercial tea dry leaves types, black and gree, were found $(p<0.05)$.

Concerning the infusions, the amount of aluminum transferred to the liquid phase was statistically different depending upon tea type, infusion time, and sucrose presence (Table 4). 
Table 1. Concentrations of aluminum in commercial black and green dry tea leaves.

\begin{tabular}{|c|c|c|c|c|c|c|}
\hline & \multicolumn{2}{|c|}{$\begin{array}{l}\text { Aluminum contents in dry leaves (ppm or } \\
\qquad \mathrm{mg} \cdot \mathrm{kg}^{-1} \text { ) }\end{array}$} & \multicolumn{2}{|c|}{ Aluminum percentage ( $\%$ d.m.) } & \multicolumn{2}{|c|}{$\begin{array}{l}\text { Aluminum contents per pouch of tea } \\
\qquad(\mathrm{mg})\end{array}$} \\
\hline & Green tea & Black tea & Green tea & Black tea & Green tea & Black tea \\
\hline Media & 1322.56 & 1114.20 & 0.13 & 0.11 & 1.28 & 1.08 \\
\hline S. D. & 256.91 & 58.61 & 0.03 & 0.01 & 0.26 & 0.05 \\
\hline V.C. & 19.42 & 5.26 & 23.07 & 9.09 & 20.31 & 4.62 \\
\hline
\end{tabular}

S. D.: standard deviation, V. C.: variation coefficient, d. m.: dry matter.

Table 2. Concentrations of aluminum found in sucrose, water, and pouches material.

\begin{tabular}{|c|c|}
\hline Sample & Aluminum contents (ppm or $\mathrm{mg} \cdot \mathrm{kg}^{-1}$ ) \\
\hline Sucrose & $<$ D. L. \\
\hline Pouch material & $<$ D. L. \\
\hline Dinking water (commercial carafe) & 1.55 \\
\hline
\end{tabular}

D. L.: Detection limit.

Table 3. Aluminum concentrations in black and green tea infusions.

\begin{tabular}{lcc}
\hline \multicolumn{1}{c}{ Treatments } & $\begin{array}{c}\text { Aluminum in black tea infusions } \\
\left(\mathbf{p p m ~ o r ~} \mathbf{~ m} \cdot \mathbf{k g}^{-1}\right)\end{array}$ & $\begin{array}{c}\text { Media } \\
\text { Aluminum in green tea infusions } \\
\left(\mathbf{p p m ~ o r ~} \mathbf{~ m g} \cdot \mathbf{k g}^{-1}\right) \mathbf{M e d i a}\end{array}$ \\
\hline T-5 (5 min infusion) & $0.46 \pm 0.00$ & $0.61 \pm 0.00$ \\
T-15 (15 min infusion) & $0.65 \pm 0.05$ & $0.65 \pm 0.05$ \\
T-A-5 (5 min, ascorbic acid added) & $0.34 \pm 0.05$ & $0.57 \pm 0.16$ \\
T-A-15 (15 min, ascorbic acid added) & $0.57 \pm 0.05$ & $0.46 \pm 0.00$ \\
T-S-5 (5 min, sucrose added) & $0.53 \pm 0.00$ & $0.53 \pm 0.00$ \\
T-S-15 (15 min, sucrose added) & $0.70 \pm 0.00$ & $0.61 \pm 0.00$ \\
T-A-S-5 (5 min, ascorbic acid + sucrose added) & $0.65 \pm 0.05$ & $0.57 \pm 0.05$ \\
T-A-S-15 (15 min, ascorbic acid + sucrose & $0.61 \pm 0.00$ & $0.69 \pm 0.00$ \\
added) & & \\
\hline
\end{tabular}

A: ascorbic acid added, S: sucrose added, T: tea leaves.

Table 4. Variability analysis for aluminum dissolved in black and green tea infusions.

\begin{tabular}{cccccc}
\hline Factors & Square values sum & d.f. & Medium Square & Coefficients F & P Value \\
\hline $\begin{array}{c}\text { A) Tea type } \\
\text { (green/Black) }\end{array}$ & 0.0047531 & 1 & 0.0047531 & 0.89 & 0.3570 \\
B) Ascorbic acid & 0.0087781 & 1 & 0.0087781 & 1.64 & 0.2145 \\
C) Sucrose & 0.0399031 & 1 & 0.0399031 & 1.45 & 0.0126 \\
D) Infusion time & 0.0552781 & 1 & 0.0552781 & & 0.0042 \\
& & & & 0.07 & 0.7931 \\
A-B & 0.0003781 & 1 & 0.0003781 & 2.94 & 0.1011 \\
A-C & 0.0157531 & 1 & 0.0157531 & 4.02 & 0.0581 \\
A-D & 0.0215281 & 1 & 0.0215281 & 7.98 & 0.0101 \\
B-C & 0.0427781 & 1 & 0.0427781 & 1.76 & 0.1983 \\
B-D & 0.0094531 & 1 & 0.0094531 & 0.01 & 0.9050 \\
C-D & 0.0000781 & 1 & 0.0000781 & & \\
Residues & 0.112516 & 21 & 0.0053578 & & \\
Total (Corr.) & 0.311197 & 31 & &
\end{tabular}

Quotients F are based on the quadratic mean residual error (d.f. degrees of freedom). P value is the probability of obtaining a test statistic (which is a function of the sample; it is considered as a numerical summary of a set of data that reduces the data to one or a small number of values that can be used to perform a hypothesis test) at least as extreme as the one that was actually observed, assuming that the null hypothesis is true (general or default position, such as that there is no relationship between two measured phenomena, or that a potential treatment has no effect). 
Irrespective of the type of tea, infusion time is an important factor concerning the amount of dissolved aluminum. In the case of sucrose, it seems this factor is relevant, since its chemical structure may be inducing the release of aluminum from the polyphenol complex structures in tea. This might be an important line of research to be followed in the future, especially in those countries where sugar is added at the time of leaves infusion.

Also, aluminum speciation should be carried out, since some chemical species are more prone to be biologically active $[9,22-26]$.

\section{Conclusions and Recommendations}

Contents of aluminum in the most widely consumed commercial dry leaves of green and black tea found in Mexico City's supermarkets and its infusions were assessed. Average concentrations are higher in green tea with respect to black tea but the differences were not statistically significant $(\mathrm{p}<0.05)$.

Statistically $(p<0.05)$, the most influencing factors in the infusions of both types of tea were the infusion time and the sugar contents (sucrose). Also, the interaction of ascorbic acid and sucrose seemed to play a role, particularly with black tea.

According to the Mexican Standards for drinking water [21], the maximum concentration of aluminum is 0.2 $\mathrm{ppm}$. For the infusions, the drinking water contents were deducted from the total values obtained for all infusions, and even though all of them exceeded this norm.

Commercially sold drinking water in Mexican supermarkets, and used in these experiments, contained 1.55 ppm aluminum, a value far exceeding this limit, a fact that should be assessed by the sanitary authorities in Mexico. Finally, it is recommended to assess the aluminum species found in the dry tea leaves and in the infusions to evaluate its bioavailability for potential consumers $[7,9,23,25,27]$.

\section{Acknowledgements}

One of the authors acknowledges the scholarship granted to pursue doctoral studies to UNAM (National Autonomous University of Mexico in Spanish) Coordination for Graduate Studies. Materials were partially acquired with a UNAM DGAPA project (PAPIME PE101709 “Apoyo a la enseñanza experimental de las asignaturas terminales de las carreras que se imparten en la Facultad de Química de la UNAM"). Authors appreciate the technical support from M.A.I. Landy Irene Ramírez-Burgos.

\section{REFERENCES}

[1] T. Yamamoto, L. R. Juneja, D. C. Chu and M. Kim, (Eds.), "Chemistry and Applications of Green Tea," CRC
Press, Florida, 1997.

[2] A. Cruz-Bárcenas, "Boom in the Tea Consumption in Mexico, it grows annually 20\%," 16 November 2007, (Active 4 January 2009).

http://www.jornada.unam.mx/2007/11/16/index.php?secti on= gastronomia \&article $=$ a $10 \mathrm{n} 1$ gas

[3] J. Y. Ruan and M. H. Wong, "Accumulation of Fluoride and Aluminum Related to Different Varieties of Tea Plant," Environmental Geochemistry and Health, Vol. 23, 2001, pp. 53-63. doi:10.1023/A:1011082608631

[4] H. Matsumoto, E. Hirasawa, S. Morimura and E. Takahashi, "Localization of Aluminum in Tea Leaves," Plant and Cell Physiology, Vol. 17, No. 3, 1976, pp. 627-631.

[5] J. A. T. Pennington, "Aluminum Content of Foods and Diets," Foods Additives and Contaminants, Vol. 5, 1988, pp. 161-232.

[6] P. O. Owuor, F. O. Gone, D. B. Onchiri and I. O. Jumba, "Levels of Aluminum in Green Tea Leaf of Clonal Tea, Black Tea Liquors, and Effects of Rates of Nitrogen Fertilizers on the Aluminum Black Tea Contents," Food Chemistry, Vol. 35, 1990, pp. 59-69. doi:10.1016/0308-8146(90)90131-M

[7] C. Steinhausen, G. Kislinger, C. Winklhofer, E. Beck, C. Hohl, E. Nolte, T. H. Ittel and M. J. Álvarez-Bruckmann, "Investigation of the Aluminumm Biokinetics in Humans: A ${ }^{26} \mathrm{Al}$ Tracer Study," Food Chemical Toxicology, Vol. 42, No. 3, 2004, pp. 363-371. doi:10.1016/j.fct.2003.09.010

[8] M. H. Wong, Z. Q. Zhang, J. W. C. Wong and C. Y. Lan, "Trace Metal Contents (Al, Cu and $\mathrm{Zn}$ ) of Tea: Tea and Soil from Two Tea Plantations, and Tea Products," Environmental Geochemistry Health, Vol. 20, No. 2, 1998, pp. 87-94. doi:10.1016/j.fct.2008.09.041

[9] R. A. Yokel and R. L. Florence, "Aluminum Availability from Tea Infusion," Food and Chemical Toxicology, Vol. 46, 2008, pp. 3659-3663.

[10] J. R. J. Sorenson, I. R. Campbell, 1. B.Tepper and R. D. Lingg, "Aluminum in the Environment and Human Health," Environmental Health Perspectives, Vol. 8, 1974, pp. 3-95. doi:10.1289/ehp.7483

[11] K. F. Fung and M. H. Wong, "Effects of Soil pH on the Uptake of Aluminum, Fluoride and Other Elements by Tea Plants," Journal of Science of Food \& Agriculture, Vol. 82, 2001, pp. 1-7.

[12] K. F. Fung, Z. Q. Zhang, J. W. C. Wong and M. H. Wong, "Aluminum and Fluoride Concentrations of Three Tea Varieties Growing at Lantau Island, Hong Kong," Environmental Geochemistry Health, Vol. 25, No. 2, 2003, pp. 219-232.

[13] D. R. C. McLachlan, "Aluminum and the Risk for Alzheimer's Disease," Environmentrics, Vol. 6, No. 6, 1995, pp. 233-275.

[14] A. Campbell and S. C. Bondy, "Aluminum Induced Oxidative Events and Its Relation to Inflammation: A Role for the Metal in Alzheimer's Disease," Cellular Molecular Biology, Vol. 46, No. 4, 2000, pp. 721-730. 
[15] C. Exley and J. Korchazhkina, "Promotion of Formation of Amyloid Fibrils by Aluminum Adenosine Triphosphate (AlATP)," Journal of Inorganic Biochemistry, Vol. 84, No. 3-4, 2001, pp. 215-224. doi:10.1016/S0162-0134(01)00171-4

[16] T. P. Flaten, "Aluminum in Tea-Concentrations, Speciation and Bioavailability," Coordination Chemistry Reviews, Vol. 228, 2002, pp. 385-395. doi:10.1016/S0010-8545(02)00036-X

[17] M. A. Moghaddam, A. H. Mahvi, A. R. Asgari, M. Yonesian, G. H. Jahed and S. H. Nazmara, "Determination of Aluminum and Zinc in Iranian Consumed Tea," Environmental Monitoring Assessment, Vol. 11, No. 1-3, 2008, pp. 22-30.

[18] M. H. Wong, K. F. Fung and H. P. Carr, "Aluminum and Fluoride Contents of Tea, with Emphasis on Brick Tea and Their Health Implications," Toxicology Letters, Vol. 137, 2003, pp. 111-120. doi:10.1016/S0378-4274(02)00385-5

[19] D. A. Bárcena-Padilla, "Aluminum Contents in Infusions of Commercial Tea Leaves with and without Sugar and with and without Lemon Juice at Two Different Infusion Times," Ph.D. Thesis, Universidad Nacional Autónoma de México, Mexico City, 2010.

[20] J. L. Stauber, T. M. Florence, C. M. Davies, M. S. Adams and S. J. Buchanan, "Bioavailability of Al in AlumTreated Drinking Water," Journal of American Water Works Association, Vol. 91, 1999, pp. 84-93.

[21] Official Diary of the Federation (ODF), "Official Mexican Standards NOM-127-SSA1-1994. Environmental Hea1th. Water for Use and Human Consumption," Official Diary of the Federation, Mexico City, 1994.
[22] J. P. Boudot, T. Becquer, D. Merlet and J. Rouiller, "Aluminium Toxicity in Declining Forests: A General Overview with Seasonal Assessment in a Silver Fir Forest in the Vosges Mountains (France)," Annals of Forest Science, Vol. 51, No. 1, 1994, pp. 27-51. doi:10.1051/forest: 19940103

[23] D. Krewski, R. A. Yokel, E. Nieboer, D. Borchelt, J. Cohen, J. Harry, S. Kacew, J. Lindsay, A. M. Mahfouz and V. Rondeau, "Human Health Risk Assessment for Aluminum, Aluminum Oxide, and Aluminum Hydroxide," Journal Toxicology Environmental Health Part B: Critical Review, Vol. 10, Suppl. 1, 2007, pp. 1-269.

[24] D. R. Parker and P. M. Bertsch, "Identification and Quantification of the $\mathrm{Al}_{13}$ Tridecameric Polycation Using Ferron," Environmental Science Technology, Vol. 26, 1992, pp. 908-914. doi:10.1021/es00029a006

[25] T. B. Polak, R. Milacic, B. Pihlar and B. Mitrovic, "The Uptake and Speciation of Various Al Species in the Brassica Rapa Pekinensis," Phytochemistry, Vol. 57, No. 2, 2001, pp. 189-198.

[26] J. Wu, C. Y. Zhou, M. K. Wong, H. K. Lee and C. N. Ong, "Urine Levels of Aluminum after Drinking Tea," Biological Trace Element. Research, Vol. 57, No. 3, 1997, pp. 271-280. doi:10.1007/BF02785295

[27] Y. Zhou, W. R. Harris and R. A. Yokel, "The Influence of Citrate, Maltolate, and Fluoride on the Gastrointestinal Absorption of Aluminum at a Drinking Water-Relevant Concentration: A ${ }^{26} \mathrm{Al}$ and ${ }^{14} \mathrm{C}$ Study," Journal Inorganic Biochemistry, Vol. 102, No. 4, 2008, pp. 798-808. doi:10.1016/j.jinorgbio.2007.11.019 